1 Effect of request for unique personal identifiers and souvenir incentives on consent to health record linkage: evidence from an RCT nested within a cohort

3

4 Michael Y. Ni ${ }^{1}$, Tom K. Li ${ }^{1}$, Rex W.H. Hui ${ }^{2}$, Ian McDowell ${ }^{3}$, Gabriel M. Leung1 5

\title{
6 Affiliations:
}

24 Running title: Effect of personal identifiers and incentives on health record linkage

1. School of Public Health, Li Ka Shing Faculty of Medicine, The University of Hong Kong, Hong Kong Special Administrative Region, China.

2. Li Ka Shing Faculty of Medicine, The University of Hong Kong, Hong Kong Special Administrative Region, China.

3. School of Epidemiology, Public Health and Preventive Medicine, University of Ottawa, Ottawa, Canada

\section{Corresponding author:}

Dr. Michael Y. Ni, School of Public Health, Li Ka Shing Faculty of Medicine, The University of Hong Kong, Hong Kong SAR, People's Republic of China.

Tel: +852 3917 6776; Fax: +852 3520 1945; email: nimy@hku.hk.

Word count (abstract): 218

Word count (main text): 1,598

Number of tables/figures: 6

Conflict of interest: All authors report no competing interests.

23 


\section{ABSTRACT}

3 Objective: It is unclear if unique personal identifiers should be requested from

4 participants for health record linkage: this permits high-quality data linkage but at the

5 potential cost of lower consent rates due to privacy concerns.

6

7 Study Design and Setting: Drawing from a sampling frame based on the FAMILY

8 Cohort, using a 2x2 factorial design, we randomly assigned 1,200 participants to: (1)

9 request for Hong Kong Identity Card number (HKID) or no request, and (2) receiving a

10 souvenir incentive (valued at USD4) or no incentive. The primary outcome was consent

11 to health record linkage. We also investigated associations between demographics,

12 health status, and postal reminders with consent.

14 Results: Overall, we received signed consent forms from 33.3\% (95\% CI 30.6\% to $36.0 \%)$ of respondents. We did not find an overall effect of requesting HKID (-4.3\%, $95 \% \mathrm{CI}-9.8 \%$ to $1.2 \%)$ or offering souvenir incentives $(2.4 \%, 95 \% \mathrm{CI}-3.1 \%$ to $7.9 \%)$ on consent to linkage. In subgroup analyses, requesting HKID significantly reduced consent among adults aged $18-44$ years (OR $0.53,95 \%$ CI 0.30 to 0.94 , compared to no request). Souvenir incentives increased consent among women (OR 1.55, 95\% CI 1.13 to 2.11, compared to no souvenirs).

Conclusions: Requesting a unique personal identifier or providing a souvenir incentive did not affect overall consent to health record linkage.

25 Keywords: Health record linkage; Data linkage; Consent; Randomised; Unique 26 identifier; Incentive 


\section{What is new?}

- Overall, requesting a unique personal identifier or providing a souvenir incentive did not significantly affect consent to health record linkage. Thus in this context, unique personal identifiers should be requested to enable higher precision in health record linkage.

- However, the effect of the interventions varied by age and sex: younger respondents were less likely to provide consent when asked to provide a unique personal identifier, whereas incentives increased consent among young people and women.

- Postal invitations may still be a relatively inexpensive, useful initial strategy to obtain consent for health record linkage. 


\section{INTRODUCTION}

2 As participation rates continue to decline for academic research, government or

3 industry surveys (1), data linkage to administrative and medical records provides an

4 important alternative to access routinely collected data while minimising respondent

5 burden (2). Yet low consent rates to health record linkage and response bias are

6 frequent challenges (2-4). Age (5-9), ethnic minority status $(6,7,10,11)$, education level

$7(5,7,8)$, household income $(5,6)$, area of residence $(6,10)$, health status $(5,7,12)$,

8 chronic metabolic diseases (5), depressive symptoms (12), and health services

9 utilisation (7) have been associated with consent, although inconsistencies remain (7-9,

10 11, 12). In addition, while cash incentives appear to increase response to mail surveys

11 or other survey modalities (13-16), it is unclear whether incentives influence consent

12 for data linkage (17), and whether souvenir incentives are effective.

14 Data linkage can be achieved in two ways. Deterministic linkage uses a unique personal 15 identifier - such as the Hong Kong Identity Card number (HKID), or the Social Security 16 number in the US or the National Health Service number in the UK - to link information 17 contained in different datasets. The advantage of a unique identifier is higher health record linkage success. However, HKID numbers are also used in banking services and as authentication for password changes, thus are generally regarded as sensitive personal data (18). Privacy concerns have been shown to be negatively associated with consent in observational studies $(19,20)$. The second option, probabilistic linkage, uses personal data such as name and date of birth to circumvent the need for unique personal identifiers but may result in duplicate matches. The choice is therefore unclear: unique personal identifiers permit high quality data linkage but at the potential cost of lower consent rates. We accordingly tested the effect of 1 ) requesting a unique 
1 personal identifier and 2) providing a small, souvenir incentive on consent to health

2 record linkage, using a randomised factorial design. A secondary objective was to

3 identify whether respondent characteristics and the use of postal reminders were

4 related to consent.

5

6 METHODS

\section{$7 \quad$ Study design and participants}

8 We nested a randomised controlled trial within the FAMILY Cohort (total $N=46,001$ ), a

9 population-based longitudinal study described in detail elsewhere (21). Participants

10 were drawn from a subsample of the FAMILY Cohort where one member from each

11 household was randomly selected to form the sampling frame. Eligibility was defined

12 by age $\geq 18$ years and completion of two waves of in-person follow-ups. We used a 2-by-

132 factorial design to randomly assign 1,200 adult participants to: (1) request for

14 personal unique identifier (HKID) or no request, and (2) receive a souvenir incentive or

15 no incentive. Randomisation sequence was created using Stata MP 13.1 (StataCorp,

16 College Station, TX), and was stratified by sex, age group and educational attainment

17 (Figure 1). All participants were blinded to the randomised design. The study was approved by the Institutional Review Board of the University of Hong Kong/Hospital Authority Hong Kong West Cluster.

21 All respondents received identical invitation letters, an information leaflet, a consent

22 form and a prepaid return envelope by mail. For respondents allocated to receive HKID

23 requests, their consent form included a box to fill in their HKID and, as an alternative, a

24 secure web link to enter the HKID (Figure 1). Either was accepted. Those allocated to receive a souvenir incentive were mailed an upfront souvenir including a FAMILY 
1 Cohort-branded washcloth, a set of chopsticks and a rice paddle, with a collective value

2 of USD 4. Two reminder letters were sent 20 days and 33 days after the initial mailing.

3 We allowed 60 days as the cut-off period for return of completed consent forms.

4

$5 \quad$ Primary analysis

6 The primary outcome was receipt of written consent to health record linkage by

7 intention-to-treat. We needed an overall sample size of 1,188 (alpha $=0.025$ and power

$8=0.90$ ) for the 2 factorial comparisons (hence, overall alpha $=0.05$ and power $=0.81$ ) in

9 order to detect a $10 \%$ absolute difference in consent proportion between (1) HKID

10 request vs. no request, and (2) souvenir incentive vs. no incentive (22). The expected

11 consent proportion for the control group was 35\%. We used the chi-square test to

12 compare the proportions consenting between the four groups. We then used

13 multivariable logistic regression and the likelihood ratio test to perform interaction

14 analyses to test whether the effect of requesting HKID varied according to whether

15 participants were randomly assigned to receive a souvenir incentive. Similarly, we

16 performed tests for interactions between the interventions and demographic subgroups

17 (age, sex, education level and household income) by adding treatment subgroup

18 interaction terms to the models.

19

\section{Secondary analyses}

21 We assessed associations between baseline predictors assessed at wave 2 including

22 demographics and health status (physical and mental well-being using the SF-12v2 (23,

23 24), chronic disease status and hospital admission) with consent using multivariable

24 logistic regression with Bonferroni correction for multiple comparisons. Each baseline 
1 predictor was examined in a separate regression model, adjusting for age, sex,

2 education level, employment status and household income.

3

4 Additionally we examined whether the two postal reminders were associated with a

5 significant change in the daily consent rates using segmented logistic regression (25).

$6 \quad$ All analyses were done using R version 3.3.0.

7

\section{RESULTS}

9 Participants ( $n=1,200)$ were randomly allocated into four groups: 1$)$ HKID request and incentive ( $n=292) ; 2)$ HKID request without incentive $(n=306) ; 3)$ incentive without

11 HKID request ( $n=303) ; 4)$ no incentive and no HKID request $(n=299)$. Baseline

12 characteristics were balanced in the four groups (Table 1).

14 Consent by group

15 The proportions consenting were, in descending order, 36.6\% (95\% CI 31.2\%-42.3\%)

16 in the group with an incentive and without a HKID request, $34.1 \%(28.8 \%-39.8 \%)$ in the

17 control group receiving no incentive and no HKID request; $32.2 \%(26.9 \%-37.9 \%)$ in the

18 group receiving both incentive and request, and $30.1 \%(25.0 \%-35.5 \%)$ among the

19 group receiving HKID request without an incentive. There was no interaction between

20 the two interventions $(\mathrm{P}=0.96)$.

21

Effect of HKID request

23 Participants in the two groups that received an HKID request had a 4.3\% lower absolute 24 consent (31.1\%, 95\% CI 27.4\%-35.0\%) compared to those not asked to give their ID 25 (35.4\%, 95\% CI 31.6\%-39.3\%); the difference was not significant $(\mathrm{P}=0.14)$. 
2 Effect of souvenir incentive

3 Those who received a souvenir incentive had a $2.4 \%$ higher absolute consent

4 proportion (34.5\%, 95\% CI 30.6\%-38.4\%) compared to those without the incentive

$5 \quad$ (32.1\%, 95\% CI 28.4\%-35.9\%); this difference was also not significant $(\mathrm{P}=0.38)$.

6

$7 \quad$ Interaction between demographics and interventions

8 Subgroup analysis shows that the effect of requesting the HKID varied according to age,

9 where requesting HKID reduced consent proportions among younger adults but not

10 among middle-aged or older adults (Figure 2). Provision of a souvenir incentive

11 increased consent proportions among young adults and women (Figure 3).

12

13 Demographic correlates of giving consent

14 In the overall sample, older age and higher household income were associated with consent to health records linkage (Table 2). However, only age remained significant

16 after correction for multiple comparisons. Other demographic characteristics and

17 indicators of health status were not associated with consent.

18

Effect of postal reminders

20 There were clear temporal associations of receiving completed consent forms with each

21 of the two reminder mailings (Figure 4, upper panel). Seven breakpoints in the daily

22 consent rate were identified over time (Figure 4, lower panel). The daily consent rate

23 increased substantially after the third (Day 20) and the fifth (Day 32) breakpoints,

24 which correspond to the first and the second postal reminders. 


\section{DISCUSSION}

2 We did not find an overall effect of requesting a unique personal identifier on consent to

3 health record linkage. However, younger respondents were less likely to provide

4 consent when asked to provide HKID (Figure 2), which is consistent with younger

5 individuals having more privacy concerns about health record linkage $(8,26)$.

6 Comparison of responders and non-responders showed that older age was associated

7 with consent (Table 2). There were no systematic differences regarding other

8 demographic characteristics or health status.

9

10 We also did not find an overall effect of providing a souvenir incentive on consent,

11 although incentives increased consent among younger people and women (Figure 3).

12 The effect of the interventions did not vary by socioeconomic status. Our overall null

13 effect for incentives could be attributed to the use of souvenirs rather than monetary

14 incentives $(13-15,27)$. In addition, the incentives may not have increased consent

15 proportions as participants were drawn from a cohort that has previously received

16 similar incentives over a number of years.

18 Possible reasons for the low consent rate in our study include the use of postal

19 invitations. Postal invitations are less costly but yield lower response rates compared to

20 face-to-face interviews (28). Our level of consent is comparable to previous studies

21 using postal invitations for health record linkage $(3,4)$. Moreover, a multi-ethnic

22 national cohort study found that individuals of Asian ethnicity are less likely to consent

23 with health records linkage (10). However, the study also identified higher educational

24 attainment to be negatively associated with consent (10). The inconsistent findings for 
1 socioeconomic status and health status as predictors of giving consent suggest that

2 these associations could be contextually specific $(7-9,11,12)$.

3

4 Our findings are subject to certain limitations. First, our trial was powered to detect a

$5 \quad 10 \%$ difference between groups and thus would not be expected to detect smaller effect

6 sizes as in the present study. Second, as the randomised trial was nested within a

7 cohort, our findings may have limited generalisability to de novo studies that are

8 contacting participants for the first time. In those settings, the effect of requesting

9 unique personal identifiers and provision of incentives may be larger. However, our

10 original sample was randomly drawn from the community and therefore generalisable

11 to other population-based studies.

12

13 In conclusion, our trial demonstrated that the request for a unique personal identifier

14 did not substantially reduce consent proportions. Our findings add to the literature on

15 demographic variation in study participation (1), in that there may well be age-based

16 variability for providing sensitive identifying information. Although only one-third of

17 those approached consented to health record linkage, postal invitations could still be a

18 relatively inexpensive, useful initial strategy for cohort studies.

19 


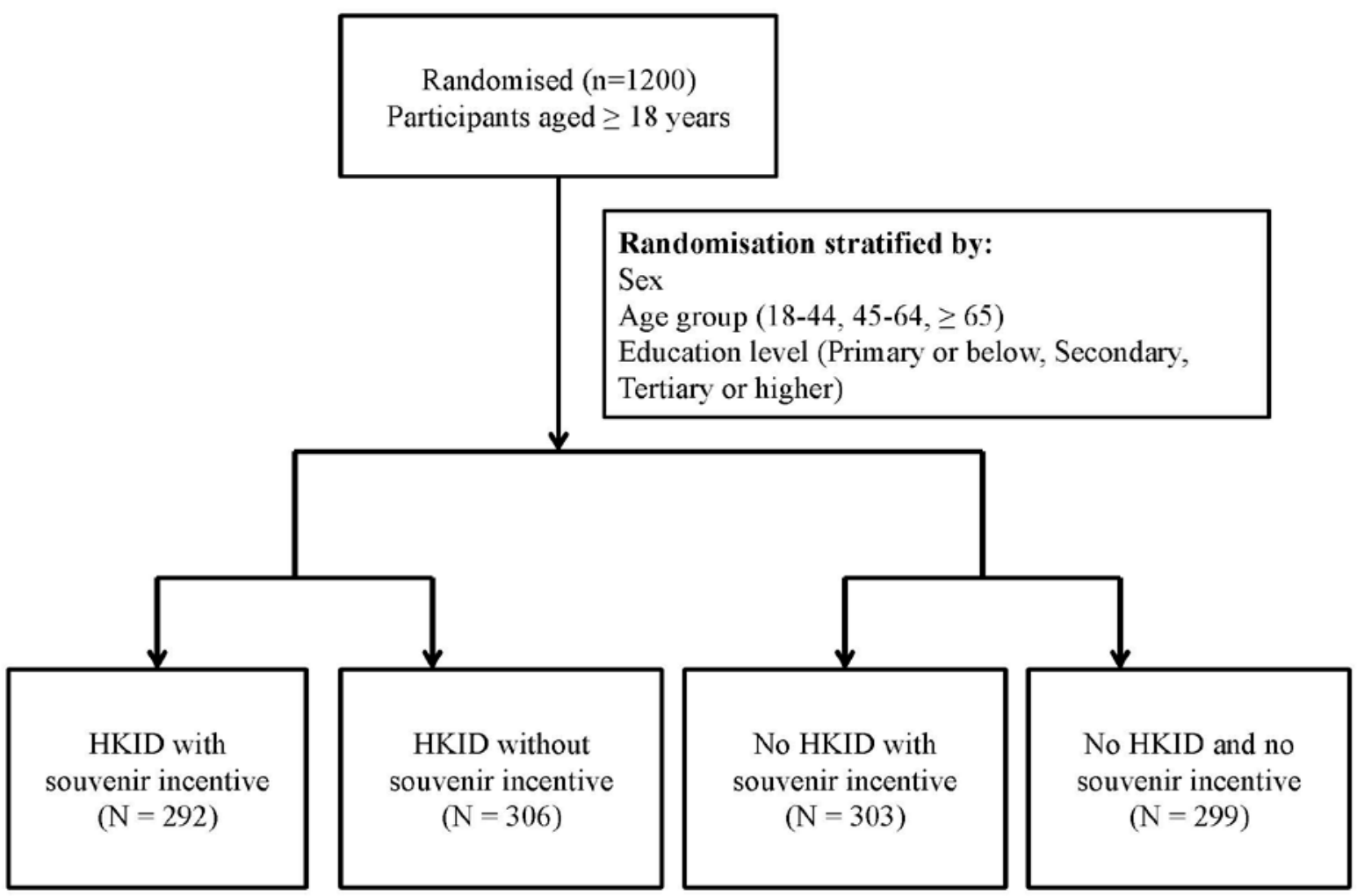

4

5 Figure 1. Randomised Allocation of Request for Hong Kong Identity Card number

6 (HKID) and Souvenir Incentive.

7

8 


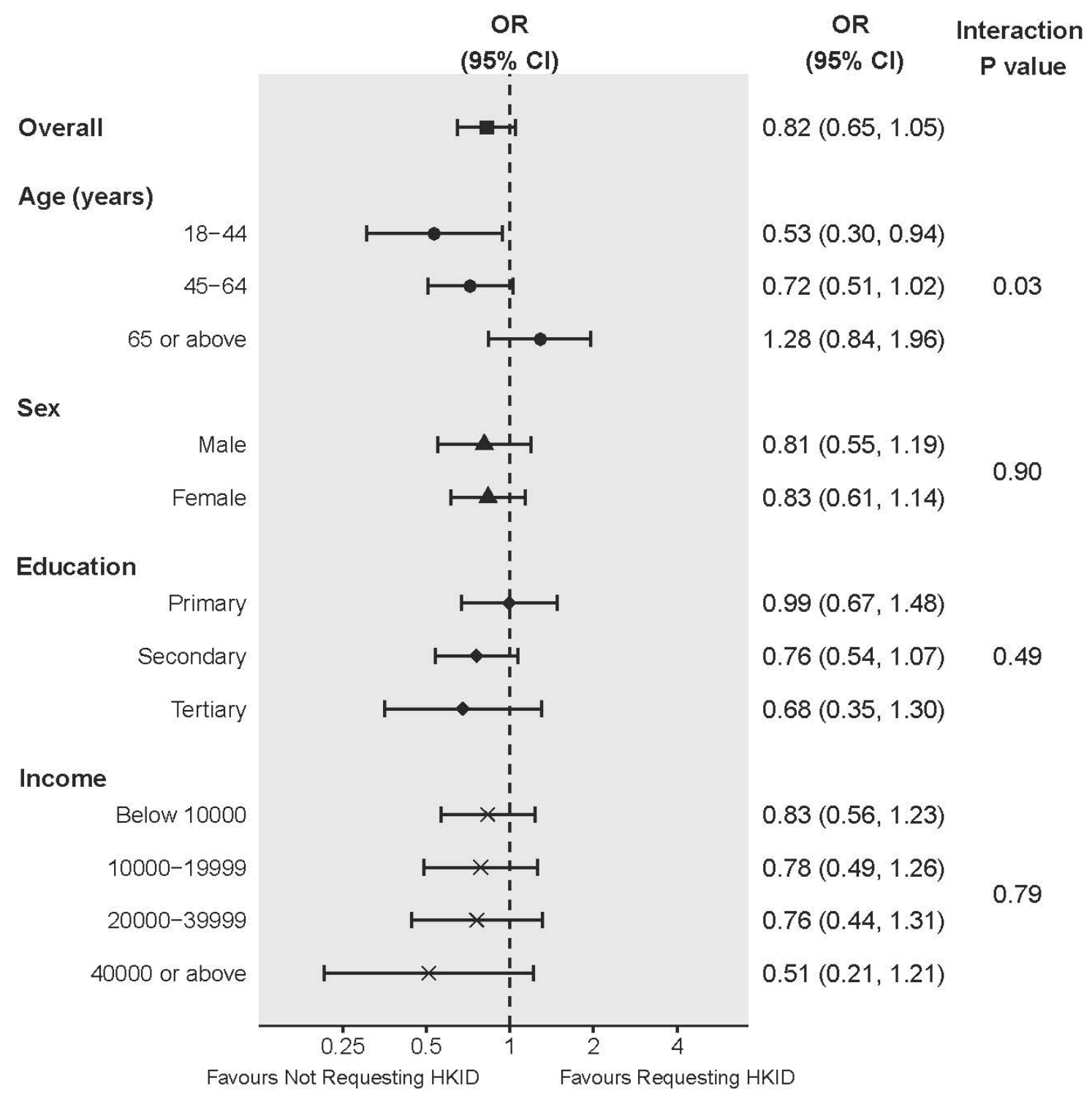

1

2 Figure 2. Effect of Requesting Hong Kong Identity Card number (HKID) According

3 to Demographic Subgroups. P values were obtained from the likelihood ratio tests of

4 the interaction terms of requesting HKID and the subgroups.

5 


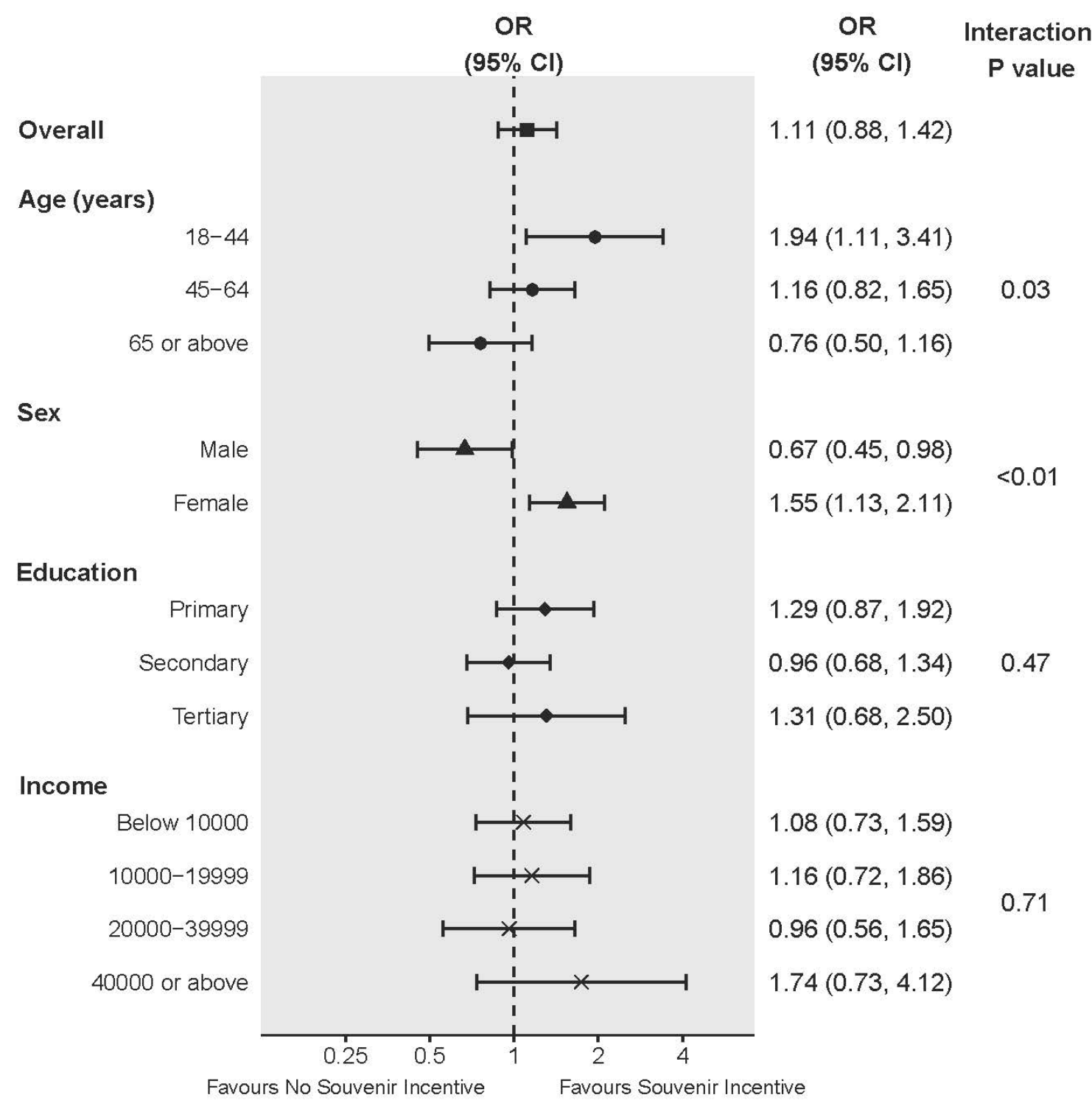

2 Figure 3. Effect of Providing Souvenir Incentives According to Demographic

3 Subgroups. P values were obtained from the likelihood ratio tests of the interaction

4 terms of souvenir incentives and the subgroups.

5 

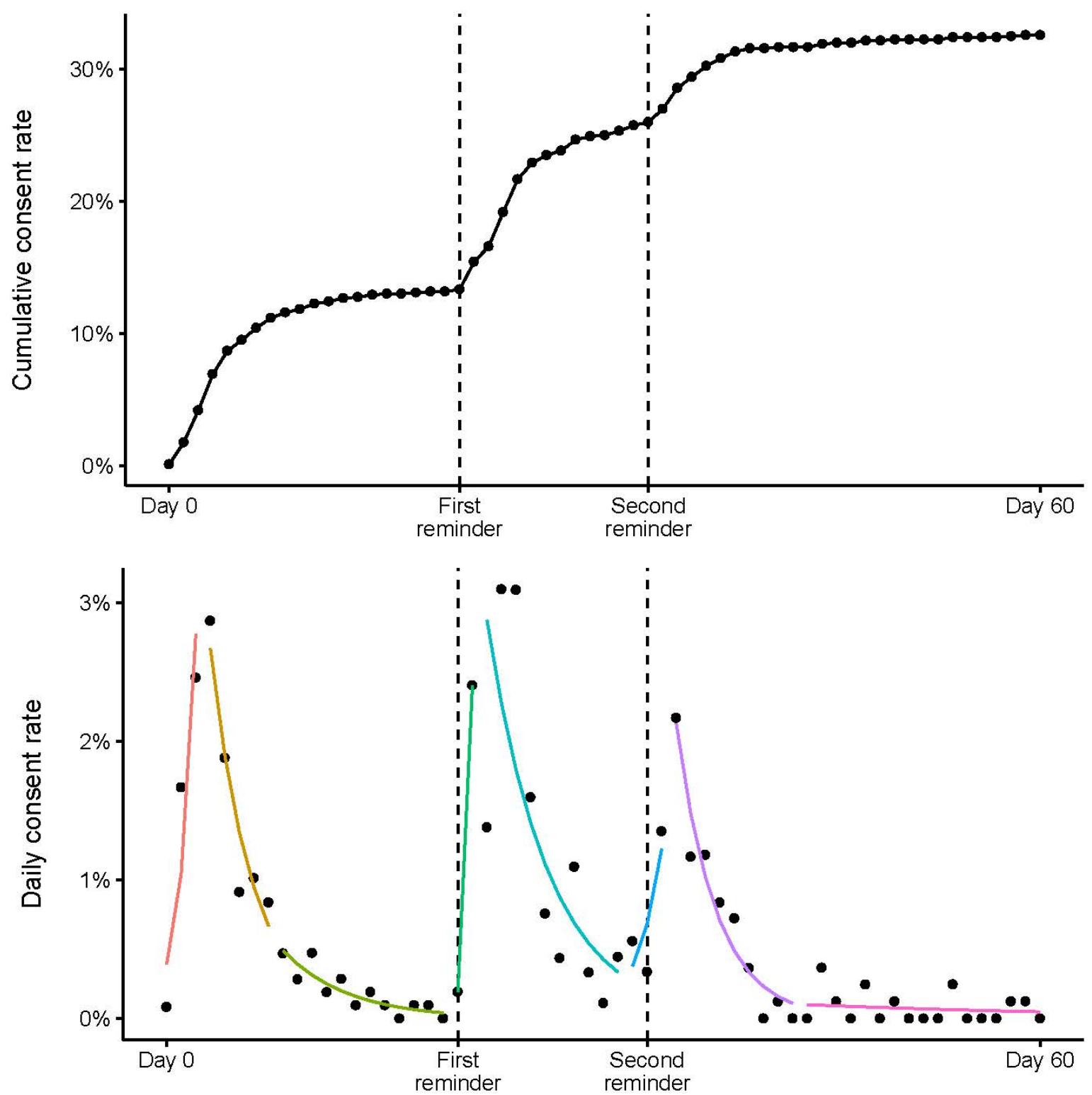

2 Figure 4. Cumulative and Daily Consent Rates. The upper panel shows the temporal

3 associations of receiving completed consent forms with each of the two reminder

4 mailings. The lower panel shows time points where there was a change in daily consent

$5 \quad$ rates as indicated by breakpoints between fitted lines.

6 
Table 1. Baseline Characteristics of the Study Participants

\begin{tabular}{|c|c|c|c|c|c|c|c|c|}
\hline & \multicolumn{4}{|c|}{ HKID request } & \multicolumn{4}{|c|}{ No HKID request } \\
\hline & \multicolumn{2}{|c|}{ Incentive } & \multicolumn{2}{|c|}{$\begin{array}{c}\text { No } \\
\text { incentive }\end{array}$} & \multicolumn{2}{|c|}{ Incentive } & \multicolumn{2}{|c|}{$\begin{array}{c}\text { No } \\
\text { incentive }\end{array}$} \\
\hline & No. & $\%$ & No. & $\%$ & No. & $\%$ & No. & $\%$ \\
\hline Female sex & 182 & 62.3 & 188 & 61.4 & 188 & 62 & 186 & 62.2 \\
\hline \multicolumn{9}{|l|}{ Age group, years } \\
\hline $18-44$ & 70 & 24.0 & 75 & 24.5 & 74 & 24.4 & 72 & 24.1 \\
\hline $45-64$ & 131 & 44.9 & 135 & 44.1 & 135 & 44.6 & 135 & 45.2 \\
\hline$\geq 65$ & 91 & 31.2 & 96 & 31.4 & 94 & 31.0 & 92 & 30.8 \\
\hline \multicolumn{9}{|l|}{ Educational attainment } \\
\hline Primary & 106 & 36.3 & 111 & 36.3 & 110 & 36.3 & 109 & 36.5 \\
\hline Secondary & 145 & 49.7 & 149 & 48.7 & 147 & 48.5 & 146 & 48.8 \\
\hline Tertiary & 41 & 14.0 & 46 & 15.0 & 46 & 15.2 & 44 & 14.7 \\
\hline \multicolumn{9}{|l|}{ Employment status } \\
\hline Economically inactive & 159 & 54.6 & 161 & 52.8 & 159 & 52.5 & 163 & 54.5 \\
\hline Unemployed & 7 & 2.4 & 4 & 1.3 & 3 & 1.0 & 5 & 1.7 \\
\hline Employed & 125 & 43.0 & 140 & 45.9 & 141 & 46.5 & 131 & 43.8 \\
\hline \multicolumn{9}{|l|}{ Monthly income (HKD) } \\
\hline$<10000$ & 111 & 41.4 & 115 & 39.2 & 126 & 46.3 & 125 & 46.8 \\
\hline 10000-19999 & 78 & 29.1 & 82 & 28.0 & 80 & 29.4 & 70 & 26.2 \\
\hline 20000-39999 & 56 & 20.9 & 70 & 23.9 & 46 & 16.9 & 53 & 19.9 \\
\hline$\geq 40000$ & 23 & 8.6 & 26 & 8.9 & 20 & 7.4 & 19 & 7.1 \\
\hline
\end{tabular}

Abbreviation: HKID, Hong Kong Identity Card number.

4 
Table 2. Association of Demographics and Health Status with Consent to Health Record Linkage

\begin{tabular}{|c|c|c|c|c|c|c|}
\hline \multirow[b]{2}{*}{ Baseline predictors } & \multirow[b]{2}{*}{$\mathrm{N}$} & \multirow[b]{2}{*}{ Consent \% } & \multicolumn{2}{|c|}{ Model 1} & \multicolumn{2}{|c|}{ Model 2} \\
\hline & & & OR & $95 \% \mathrm{Cl}$ & OR & $95 \% \mathrm{Cl}$ \\
\hline \multicolumn{7}{|l|}{ Demographics } \\
\hline Female sex ${ }^{\dagger}$ & 744 & $32.3 \%$ & 0.89 & $0.70,1.14$ & - & - \\
\hline \multicolumn{7}{|l|}{ Age group, years ${ }^{\dagger}$} \\
\hline $18-29$ & 94 & $9.6 \%$ & 1.00 & - & - & - \\
\hline $30-44$ & 197 & $28.9 \%$ & 3.85 & $1.89,8.68$ & - & - \\
\hline $45-59$ & 423 & $35.0 \%$ & 5.08 & $2.62,11.12$ & - & - \\
\hline $60-74$ & 307 & $40.7 \%$ & 6.49 & $3.31,14.29$ & - & - \\
\hline$\geq 75$ & 179 & $33.5 \%$ & 4.76 & $2.34,10.76$ & - & - \\
\hline \multicolumn{7}{|l|}{ Education level } \\
\hline Primary & 436 & $33.3 \%$ & 1.00 & - & 1.00 & - \\
\hline Secondary & 587 & $34.4 \%$ & 1.05 & $0.81,1.37$ & 1.13 & $0.83,1.55$ \\
\hline Tertiary & 177 & $29.4 \%$ & 0.83 & $0.57,1.22$ & 1.52 & $0.91,2.55$ \\
\hline \multicolumn{7}{|l|}{ Employment status } \\
\hline Economically inactive & 642 & $32.4 \%$ & 1.00 & - & 1.00 & - \\
\hline Unemployed & 19 & $31.6 \%$ & 0.96 & $0.33,2.47$ & 1.12 & $0.37,3.04$ \\
\hline Employed & 537 & $34.3 \%$ & 1.09 & $0.85,1.39$ & 1.25 & $0.90,1.74$ \\
\hline \multicolumn{7}{|c|}{ Monthly household income (HKD) } \\
\hline$<10000$ & 477 & $30.8 \%$ & 1.00 & - & 1.00 & - \\
\hline 10000-19999 & 310 & $33.2 \%$ & 1.12 & $0.82,1.52$ & 1.18 & $0.84,1.65$ \\
\hline 20000-39999 & 225 & $37.8 \%$ & 1.36 & $0.98,1.90$ & 1.52 & $1.05,2.20$ \\
\hline$\geq 40000$ & 88 & $39.8 \%$ & 1.48 & $0.92,2.36$ & 1.53 & $0.90,2.58$ \\
\hline \multicolumn{7}{|l|}{ Health status } \\
\hline Physical well-being (0 - 100) & - & - & 1.00 & $0.98,1.01$ & 1.00 & $0.98,1.02$ \\
\hline Mental well-being $(0-100)$ & - & - & 1.00 & $0.98,1.01$ & 1.00 & $0.98,1.01$ \\
\hline \multicolumn{7}{|c|}{$\begin{array}{l}\text { Diagnosed with chronic metabolic } \\
\text { or psychiatric disorders }{ }^{a}\end{array}$} \\
\hline No & 876 & $32.6 \%$ & 1.00 & - & 1.00 & - \\
\hline Yes & 324 & $34.9 \%$ & 1.10 & $0.84,1.44$ & 0.95 & $0.70,1.29$ \\
\hline \multicolumn{7}{|c|}{ Admitted to a hospital in past year } \\
\hline No & 1114 & $33.7 \%$ & 1.00 & - & 1.00 & - \\
\hline Yes & 86 & $27.9 \%$ & 0.76 & $0.46,1.23$ & 0.77 & $0.46,1.28$ \\
\hline
\end{tabular}

Abbreviation: OR, Odds ratio; $\mathrm{Cl}$, Confidence interval.

Model 1: unadjusted

Model 2: adjusted for age, sex, education level, employment status and household income

${ }^{+}$We present unadjusted models only for age and sex as other covariates could not be common causes of these exposures and outcomes

a Self-reported doctor-diagnosed chronic metabolic diseases (hypertension, diabetes and hyperlipidaemia) or psychiatric disorders (depression, anxiety disorder or schizophrenia) 


\section{ACKNOWLEDGMENTS}

2

3 The Hong Kong Jockey Club Charities Trust funded the establishment of the original

4 cohort from 2007 to 2014. We thank Dr. Herbert Pang, Dr. Brandford Chan, Ms. Cynthia

5 Yau and Ms Betty Yuan for comments and technical assistance.

6

7 Competing interests: None

8

9 


\section{References}

1. Galea S, Tracy M. Participation rates in epidemiologic studies. Ann Epidemiol. 2007;17(9):643-53.

2. Jutte DP, Roos LL, Brownell MD. Administrative record linkage as a tool for public health research. Annu Rev Public Health. 2011;32:91-108.

3. Klassen AF, Lee SK, Barer M, Raina P. Linking survey data with administrative health information: characteristics associated with consent from a neonatal intensive care unit follow-up study. Can J Public Health. 2005;96(2):151-4.

4. Boyd A, Tilling K, Cornish R, Davies A, Humphries K, Macleod J. Professionally designed information materials and telephone reminders improved consent response rates: evidence from an RCT nested within a cohort study. J Clin Epidmiol. 2015;68(8):877-87.

5. Huang N, Shih SF, Chang HY, Chou YJ. Record linkage research and informed consent: who consents? BMC Health Serv Res. 2007;7:18.

6. Cruise SM, Patterson L, Cardwell CR, O'Reilly D. Large panel-survey data demonstrated country-level and ethnic minority variation in consent for health record linkage. J Clin Epidmiol. 2015;68(6):684-92.

7. Knies G, Burton J, Sala E. Consenting to health record linkage: evidence from a multi-purpose longitudinal survey of a general population. BMC Health Serv Res. 2012;12:52.

8. Young AF, Dobson AJ, Byles JE. Health services research using linked records: who consents and what is the gain? Aust N Z J Public Health. 2001;25(5):417-20.

9. Beebe TJ, Ziegenfuss JY, Jenkins SM, Haas LR, Davern ME. Who doesn't authorize the linking of survey and administrative health data? A general population-based investigation. Ann Epidemiol. 2011;21(9):706-9.

10. Tate AR, Calderwood L, Dezateux C, Joshi H. Mother's consent to linkage of survey data with her child's birth records in a multi-ethnic national cohort study. Int J Epidemiol. 2006;35(2):294-8.

11. Knies G, Burton J. Analysis of four studies in a comparative framework reveals: health linkage consent rates on British cohort studies higher than on UK household panel surveys. BMC Med Res Methodol. 2014;14:125.

12. Harris T, Cook DG, Victor C, Beighton C, Dewilde S, Carey I. Linking questionnaires to primary care records: factors affecting consent in older people. J Epidemiol Community Health. 2005;59(4):336-8.

13. Leung GM, Ho LM, Chan MF, JM MJ, Wong FK. The effects of cash and lottery incentives on mailed surveys to physicians: a randomized trial. J Clin Epidmiol. 2002;55(8):801-7.

14. Edwards PJ, Roberts I, Clarke MJ, Diguiseppi C, Wentz R, Kwan I, et al. Methods to increase response to postal and electronic questionnaires. Cochrane Database Syst Rev. 2009(3):Mr000008.

15. David MC, Ware RS. Meta-analysis of randomized controlled trials supports the use of incentives for inducing response to electronic health surveys. J Clin Epidmiol. 2014;67(11):1210-21.

16. Chen K, Lei H, Li G, Huang W, Mu L. Cash incentives improve participation rate in a face-to-face survey: an intervention study. J Clin Epidmiol. 2015;68(2):228-33.

17. Bell K, Clark L, Fairhurst C, Mitchell N, Lenaghan E, Blacklock J, et al. Enclosing a pen reduced time to response to questionnaire mailings. J Clin Epidmiol. 2016;74:14450. 
18. The Hong Kong Computer Society. A Practical Guide for IT Managers and Progessionals on the Personal Data (Privary) Ordinance 2012 [cited 20169 June] Available from: http://www.hkcs.org.hk/en_hk/home/publication/PDPO/files/assets/downloads/publicatio n.pdf.

19. Sakshaug JW, Couper MP, Ofstedal MB, Weir DR. Linking Survey and Administrative Records: Mechanisms of Consent. Socio Meth Res. 2012;41(4):535-69.

20. Sala E, Burton J, Knies G. Correlates of Obtaining Informed Consent to Data Linkage: Respondent, Interview, and Interviewer Characteristics. Socio Meth Res. 2012;41(3):414-39.

21. Leung GM, Ni MY, Wong PT, Lee PH, Chan BH, Stewart SM, et al. Cohort Profile: FAMILY Cohort. Int J Epidemiol. 2015. doi:10.1093/ije/dyu257 [Epub January 23, 2015]

22. Faul F, Erdfelder E, Lang AG, Buchner A. G*Power 3: a flexible statistical power analysis program for the social, behavioral, and biomedical sciences. Behav Res Methods. 2007;39(2):175-91.

23. Ware J, Jr., Kosinski M, Keller SD. A 12-Item Short-Form Health Survey: construction of scales and preliminary tests of reliability and validity. Med care. 1996;34(3):22033.

24. Lam CL, Tse EY, Gandek B. Is the standard SF-12 health survey valid and equivalent for a Chinese population? Qual Life Res. 2005;14(2):539-47.

25. Muggeo VM. Estimating regression models with unknown break-points. Stat Med. 2003;22(19):3055-71.

26. The Hong Kong Federation of Youth Groups Youth Research Center. 2005 Survey of Youth Attitudes and Perceptions towards Personal Data Privacy 2006 [cited 20169 June] Available from: http://yrc.hkfyg.org.hk/news.aspx?id=0a133e82-546c-4636-aa0c319978c6fefa\&corpname $=$ yrc\&i $=2526$.

27. Stone C, Noel H, Weir D, editors. Obtaining administrative record linkage consent by mail: Examining the impact of incentives and telephone follow-up. 2013 Joint Statistical Meetings, Survey Research Methods Section; 20132013 December; Alexandria, VA: American Statistical Association.

28. Lillard LA, Farmer MM. Linking Medicare and national survey data. Ann Intern Med. 1997;127(8 Pt 2):691-5. 